\section{Major Incident Response by EMS in Hong Kong}

Dr. ChiBiu Lo

Medical Director, Ambulance Service, Fire Services Department, Hong Kong, CHINA SAR

In Hong Kong (HK), the concept of clearing the scene as soon as possible, which was viewed as a sign of ability and efficiency, has been practiced during major incident management until recent years. In the late 1990s, the Fire Services Department (FSD) Ambulance has strengthened the concept of resource management in incident response. The triage concept is executed not only at the scene level, but also at the post-scene, since most of the acute hospitals in Hong Kong have limited resources to cope with large numbers of casualties in a short period of time.

The Hospital Authority and FSD have implemented preset quotas for diversions first in the New Airport disaster contingency plan in 1997, which was later shown to be of great assistance in managing the China Airline incident on 22 August 1999. Afterwards, the preset quota practice was adopted into the management of other major incidents. This solved the problem of diversion before arrival of the Medical Control Officer. The FSD also has adopted the practice of "first crew at scene", so that the scene control and patient transfer log starts from time zero. Criteria for dispatching emergency medical teams are set to avoid wasting resources. Hospitals are paired in incident response for better coordination.

Keywords: criteria; dispatch; emergency medical team; Hong

Kong; incident management; log; quotas; resources; triage

E-mail: locb@netvigator.com

\section{The Rally Rejviz (RR) Project \\ Dr. Jirí Staña \\ Lipovská, CZECH REPUBLIC}

The Rally Rejviz (RR) is a professional exercise and competition for EMS teams. Following the inaugural Rally Rejviz in 1997, the concept of testing emergency medical, driving, and management skills in a playful, yet competitive, but foremost a real-life setting, has met with increasing enthusiasm, both nationally as well as internationally. Building on existing experience, this project aims to bring international emergency teams together in a non-threatening environment to compare performances and exchange information about techniques and approaches, while building friendships and opportunities for crossborder cooperation.

Keywords: competition; emergency medical services; Rally Rejviz; skills

E-mail: zs_jesenik@ova.pvtnet.cz 